\title{
A Theoretical Study of the Gas-Phase Pyrolysis of 2-Azidoacetic Acid
}

\author{
M. Natália D. S. Cordeiro, ${ }^{* \dagger}{ }^{\dagger}$ António A. Dias, ${ }^{\ddagger}$ M. Lourdes Costa, ${ }^{\ddagger}$ and José A. N. F. Gomes ${ }^{\dagger}$ \\ CEQUP/Faculdade de Ciências, Universidade do Porto, Rua do Campo Alegre 687, 4169-007 Porto, Portugal, \\ and CeFITec/Departamento de Física da Faculdade de Ciências e Tecnologia, Universidade Nova de Lisboa, \\ Monte da Caparica 2825, Portugal
}

Received: August 23, 2000; In Final Form: January 9, 2001

\begin{abstract}
DFT and ab initio calculations up to the MP2 level have been performed to study the pyrolysis of 2-azidoacetic acid $\left(\mathrm{N}_{3} \mathrm{CH}_{2} \mathrm{COOH}\right)$. Several molecular properties, such as conformational equilibrium, optimal geometry, ionization energies, and vibrational frequencies, have been computed for this acid. Other species involved in its pyrolysis were also fully optimized and corrected for zero-point energies. In all cases, the calculated properties agree quite well with the observed experimental data. Two types of mechanisms were analyzed for the decomposition of $\mathrm{N}_{3} \mathrm{CH}_{2} \mathrm{COOH}$. The first analyzed mechanism is a multistep process analogous to the one traditionally proposed for alkyl azides. First, either the imine $\mathrm{NHCHCOOH}$ or the nitrene $\mathrm{NCH}_{2} \mathrm{COOH}$ is formed by the release of molecular $\mathrm{N}_{2}$. Then, from these species, ejection of $\mathrm{CO}_{2}$ will produce methanimine $\left(\mathrm{NHCH}_{2}\right)$, although other reaction channels may be expected. The second mechanism involves, after an initial distortion of the $\mathrm{N}_{3} \mathrm{CH}_{2} \mathrm{COOH}$ minimum geometry, a concerted dissociation step where $\mathrm{N}_{2}$ and $\mathrm{CO}_{2}$ are simultaneously ejected, yielding directly the imine $\mathrm{NHCH}_{2}$. Accordingly to the present calculations, the second mechanism is the most favorable one, in clear agreement with recent experimental work (J. Am. Chem. Soc. 1997, 119, 6883).
\end{abstract}

\section{Introduction}

Organic azides have been known since the last century, but their study has gathered lately a renewed interest. In fact, azides due to their strong reactivity play a crucial role in organic synthesis $^{1}$ and do have important biological, pharmaceutical, and industrial applications (for an overview see refs 2-5). They are applied in the treatment of AIDS, as inhibitors of human carbonic anhydrase, or in photoaffinity labeling biological methods. Other applications include, for instance, the preparation of semiconductor materials and their use as energetic additives for solid propellants.

The mechanisms for the decomposition of azide compounds are especially attractive for various reasons. Normally, these decompositions start with the release of molecular nitrogen and, as often admitted, generate a singlet nitrene. ${ }^{6-8}$ The singlet nitrene may undergo further reactions, including intersystem crossing to its triplet ground state, thus leading to a great variety of products.

In particular, a number of experimental studies have focused on the decomposition of simple alkyl azides such as $\mathrm{N}_{3} \mathrm{CR}_{3}(\mathrm{R}$ $=\mathrm{H}$ or $\left.\mathrm{CH}_{3}\right){ }^{7-9}$ Milligan et al. ${ }^{9}$ for example, have identified methanimine $\left(\mathrm{NHCH}_{2}\right)$ and not methylnitrene $\left(\mathrm{NCH}_{3}\right)$ as the major product upon photolysis of methyl azide $\left(\mathrm{N}_{3} \mathrm{CH}_{3}\right)$. Darwent and co-workers ${ }^{7}$ suggested, however, that both the photolysis and pyrolysis of methyl azide should occur via the nitrene intermediate. Later, Bock and Dammel ${ }^{8}$ have studied systematically the pyrolysis of many alkyl azides under identical conditions. They found a rather similar pyrolysis behavior for all azides, i.e.: imines $\left(\mathrm{NRCR}_{2}\right)$ were the unique products formed upon initial extrusion of $\mathrm{N}_{2}$. Further heating yielded final products such as $\mathrm{H}_{2}$, alkanes, and the corresponding nitriles (e.g., $\mathrm{HCN})$.

\footnotetext{
$\dagger$ Universidade do Porto

$\div$ Universidade Nova de Lisboa
}

Since the work of Bock and Dammel, ${ }^{8}$ it is now generally accepted that the pyrolysis of alkyl azides should proceed in a concerted way, via coupled $\mathrm{N}_{2}$ extrusion and 1,2-R shift from $\mathrm{C}$ to $\mathrm{N}$ to give the respective imines (eq 1)

$$
\mathrm{N}_{3} \mathrm{CR}_{3} \stackrel{T_{1}}{\longrightarrow} \mathrm{NRCR}_{2}+\mathrm{N}_{2} \stackrel{T_{2}>T_{1}}{\longrightarrow} \mathrm{RCN}+\mathrm{R}_{2}+\mathrm{N}_{2}
$$

thus turning down a stepwise channel where the initial $\mathrm{N}_{2}$ splitoff yields a nitrene. Imines then rearrange through intramolecular 1,2-shift to more stable isomers such as nitriles.

According to the semiempirical calculations performed by these authors, the concerted and stepwise channels have similar activation energies, but they justify the preference for the concerted channel on the basis of the observed temperature dependence of their experimental results. They also considered that both the thermal formation of nitrene and its consecutive reactions should occur on a singlet potential energy surface, being therefore spin-allowed processes. This raises however other questions.

Singlet nitrenes are expected to be quite unstable species that immediately decompose or rearrange. ${ }^{10}$ Thus, they would be rather difficult to observe under the conditions of Bock and Dammel's experiments. ${ }^{8}$ Indeed the authors ${ }^{8}$ even pointed out that these short-lived species could only be detected under special measurement conditions such as an in inert gas matrix at low temperatures. Noteworthy here is that singlet methylnitrene has been recently observed by photodetachment spectroscopy of the parent $\mathrm{CH}_{3} \mathrm{~N}^{-}$ion. ${ }^{11}$ Finally, crossings between singlet and triplet potential surfaces may occur and give rise to other possible decomposition mechanisms involving spinforbidden processes. ${ }^{6,7}$

Only a few theoretical studies have been performed on the pyrolysis of alkyl azides. Nguyen et al. ${ }^{12}$ studied the decomposition of methyl azide by ab initio calculations including electronic 
correlation effects. They found that $\mathrm{N}_{3} \mathrm{CH}_{3}$ dissociates, in its singlet state, into $\mathrm{NHCH}_{2}$ and $\mathrm{N}_{2}$ through the concerted channel referred to above. However, in contrast with the predictions of Bock and Dammel, ${ }^{8}$ singlet $\mathrm{NHCH}_{2}$ should then decompose via a $1,1-\mathrm{H}_{2}$ elimination to give $\mathrm{HNC}$ that rapidly isomerizes to HCN. ${ }^{12}$ Later, Arenas et al. ${ }^{13 a}$ examined the pyrolysis of both methyl and ethyl azides, using similar ab initio methods and density functional techniques. Again, the concerted singlet channel was found to be preferred for the rate-limiting step of both reactions. More recently Arenas et al. ${ }^{13 \mathrm{~b}}$ reexamined the pyrolysis of methyl azide, using multiconfigurational ab initio methods, and predicted that it should follow a multistep channel via a nitrene intermediate. Moreover, $\mathrm{N}_{2}$ extrusion is the ratelimiting step and may proceed through two (isoenergetic) competitive channels: a spin-forbidden path and a spin-allowed one.

Unfortunately, there is no definite experimental evidence to date that indicates clearly which is the favored mechanism for these reactions. Also, for more complex azides, such as the 2-azidoacetic acid or azidoacetone, different pathways might be expected, such as the one-step process recently proposed by Dyke et al. ${ }^{14}$

Dyke et al. ${ }^{14 \mathrm{a}}$ studied the gas-phase pyrolysis of 2-azidoacetic $\left(\mathrm{N}_{3} \mathrm{CH}_{2} \mathrm{COOH}\right)$ by matrix isolation infrared spectroscopy (IR) and ultraviolet photoelectron spectroscopy (PE). They have observed simultaneous formation of $\mathrm{NHCH}_{2}, \mathrm{CO}_{2}$, and $\mathrm{N}_{2}$ upon initial decomposition of $\mathrm{N}_{3} \mathrm{CH}_{2} \mathrm{COOH}$ above $650 \mathrm{~K}$. Moreover, no evidence was found for the presence of intermediates such as the nitrene $\mathrm{NCH}_{2} \mathrm{COOH}$ or the imine $\mathrm{NHCHCOOH}$. At higher temperatures $(T>900 \mathrm{~K})$, formation of $\mathrm{HCN}$ was detected, indicating the decomposition of $\mathrm{NHCH}_{2}$.

By analogy with the previous work on the decomposition of alkyl azides, stepwise reaction mechanisms of the type shown below might be envisaged (Scheme 1).

On the basis provided by the experimental results, Dyke et al. ${ }^{14 \mathrm{a}}$ argued, however, that the initial pyrolysis of azidoacetic acid should occur via a concerted pathway involving the formation of a five-membered ring transition state (Scheme 2).

This work attempts to clarify the mechanism of the gas-phase pyrolysis of the 2-azidoacetic acid from a computational point of view. The two schemes above depicted will be analyzed and compared to establish the most probable mechanism. No quantum calculations seem to have yet been reported for this pyrolysis.

\section{Computational Details}

To discuss the importance of electronic correlation effects and to assess the dependence of the results on the basis set, the molecular properties of the azidoacetic acid have been computed with several quantum models and basis sets. Namely, calculations have been carried out at the Hartree-Fock (HF) level, at the second-order Møller-Plesset perturbation level of theory (MP2), and by density functional theory (DFT), using the standard $6-31 G^{* *}$ and the $6-311 G^{* *}$ basis sets. In the DFT calculations, the Lee, Yang, and Parr ${ }^{15}$ correlation functional was used together with either the Becke ${ }^{16}$ (BLYP) or the Becke's three parameter ${ }^{17}$ (B3LYP) exchange functionals. The conformational equilibrium, optimal structure, ionization energies, and vibrational spectrum of the azidoacetic acid are reported and discussed within these methods.

Equilibrium geometries for the reactions' products considered ( $\mathrm{NHCHCOOH}, \mathrm{NHCH}_{2}, \mathrm{HNC}, \mathrm{H}_{2}, \mathrm{~N}_{2}$, and $\mathrm{CO}_{2}$ ) and transition state structures were obtained using the B3LYP/6-31G** method. Vibrational frequencies and zero-point energies (ZPE)

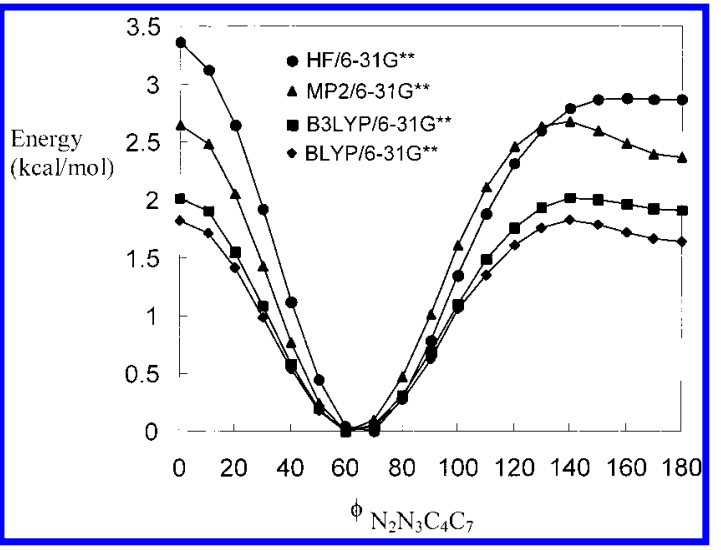

Figure 1. Rotational potential of the azidoacetic acid as a function of the NNCC dihedral angle.

for all optimized species were computed analytically with the B3LYP/6-31G** method. In some selected cases, geometries of the species were reoptimized and their corresponding ZPE computed at the MP2/6-31G** level. Unless otherwise stated, discussions of the relative energies of the relevant stationary points that follow refer to energies calculated at the B3LYP/ 6-31G**+ZPE level.

All reactant and products have been identified as true minima by the absence of imaginary frequencies. Transition state (TS) structures, on the other hand, were identified by the presence of one single imaginary frequency. In addition, transition states were always checked by intrinsic reaction coordinate (IRC) calculations. ${ }^{18}$ This allowed us to verify that we have the correct structures for the various examined reactions.

All theoretical calculations were performed using the GAUSSIAN $98^{19}$ program.

\section{Results and Discussion}

Molecular Properties of Azidoacetic Acid. Structure. To begin with, a conformational study of the acid $\mathrm{N}_{3} \mathrm{CH}_{2} \mathrm{COOH}$ has been performed to have an idea of the minimum energy structure of this molecule. Figure 1 shows the rotational potential $V(\phi)$ obtained by varying the $\mathrm{N}-\mathrm{N}-\mathrm{C}-\mathrm{C}$ dihedral angle $(\phi)$, using several theoretical methods and the same basis set (6$\left.31 \mathrm{G}^{* *}\right)$.

Some interesting features concerning $V(\phi)$ should be commented on. HF energy values are in general higher than the other values, and this method is quite poor for dealing with the molecular structure around $\phi=0^{\circ}$. By comparing the HF and MP2 results, it can be seen that the inclusion of electronic correlation effects reduces the energy barriers between the conformers, the largest difference being the barrier between the conformers $\phi=0^{\circ}$ and $\phi=180^{\circ}(0.7 \mathrm{kcal} / \mathrm{mol})$. The DFT methods have a behavior very similar to that of the MP2 method but provide lower energy values than this method. Energy differences that amount to about $0.8 \mathrm{kcal} / \mathrm{mol}$ may be inferred.

However, the most stable structure of azidoacetic acid is predicted by all methods to be a gauche-like conformer (HF, $\phi$ $=70^{\circ} ; \mathrm{MP} 2, \mathrm{BLYP}$, and B3LYP, $\phi=60^{\circ}$ ). A full optimization of the (singlet) ground state of this conformer has thus been carried out.

Figure 2 shows the equilibrium geometry of the azidoacetic acid (AA) optimized at the B3LYP/6-31G** level and gives the labeling of the atoms. Table 1 lists some of the optimized geometric parameters obtained for this acid at the various levels of theory. For simplicity, results from HF, BLYP, and B3LYP 
TABLE 1: Selected Geometrical Parameters of 2-Azidoacetic Acid

\begin{tabular}{|c|c|c|c|c|c|c|}
\hline coordinate $^{a}$ & $\mathrm{HF} / 6-31 \mathrm{G}^{* *}$ & $\begin{array}{c}\mathrm{MP} 2 / \\
6-31 \mathrm{G}^{* *}\end{array}$ & $\begin{array}{c}\text { MP2/ } \\
6-311 \mathrm{G}^{* *}\end{array}$ & $\begin{array}{c}\text { BLYP/ } \\
6-31 \mathrm{G}^{* *}\end{array}$ & $\begin{array}{l}\text { B3LYP/ } \\
6-31 G^{* *}\end{array}$ & exptl \\
\hline$r\left(\mathrm{~N}_{1}-\mathrm{N}_{2}\right)$ & 1.098 & 1.161 & 1.153 & 1.158 & 1.139 & $1.14^{b}(1.11)^{c}$ \\
\hline$r\left(\mathrm{~N}_{2}-\mathrm{N}_{3}\right)$ & 1.238 & 1.250 & 1.243 & 1.253 & 1.241 & $1.23^{b}(1.24)^{c}$ \\
\hline$r\left(\mathrm{~N}_{3}-\mathrm{C}_{4}\right)$ & 1.450 & 1.459 & 1.459 & 1.473 & 1.460 & $1.48^{b}(1.47)^{c}$ \\
\hline$r\left(\mathrm{C}_{4}-\mathrm{C}_{7}\right)$ & 1.514 & 1.518 & 1.521 & 1.539 & 1.525 & \\
\hline$r\left(\mathrm{C}_{7}-\mathrm{O}_{8}\right)$ & 1.185 & 1.215 & 1.204 & 1.219 & 1.207 & \\
\hline$r\left(\mathrm{C}_{7}-\mathrm{O}_{9}\right)$ & 1.326 & 1.355 & 1.351 & 1.371 & 1.351 & \\
\hline$r\left(\mathrm{O}_{9}-\mathrm{H}_{10}\right)$ & 0.949 & 0.972 & 0.968 & 0.984 & 0.973 & \\
\hline$\angle\left(\mathrm{N}_{1}-\mathrm{N}_{2}-\mathrm{N}_{3}\right)$ & 173.9 & 171.2 & 171.5 & 170.0 & 171.3 & $173^{b}(174)^{c}$ \\
\hline$\angle\left(\mathrm{N}_{2}-\mathrm{N}_{3}-\mathrm{C}_{4}\right)$ & 114.0 & 115.4 & 115.2 & 116.6 & 116.2 & $114^{b}(116)^{c}$ \\
\hline$\angle\left(\mathrm{N}_{3}-\mathrm{C}_{4}-\mathrm{H}_{5}\right)$ & 106.7 & 106.7 & 106.9 & 106.5 & 106.8 & $107^{b}$ \\
\hline$\angle\left(\mathrm{N}_{3}-\mathrm{C}_{4}-\mathrm{C}_{7}\right)$ & 113.7 & 112.7 & 112.7 & 113.6 & 113.5 & $114^{c}$ \\
\hline$\angle\left(\mathrm{O}_{8}-\mathrm{C}_{7}-\mathrm{O}_{9}\right)$ & 123.6 & 124.4 & 124.5 & 124.2 & 124.1 & \\
\hline$\angle\left(\mathrm{N}_{1}-\mathrm{N}_{2}-\mathrm{N}_{3}-\mathrm{C}_{4}\right)$ & 172.2 & 175.1 & 174.8 & 173.5 & 173.4 & \\
\hline$\angle\left(\mathrm{N}_{2}-\mathrm{N}_{3}-\mathrm{C}_{4}-\mathrm{C}_{7}\right)$ & 66.1 & 62.4 & 64.2 & 63.3 & 62.7 & \\
\hline$\angle\left(\mathrm{N}_{3}-\mathrm{C}_{4}-\mathrm{C}_{7}-\mathrm{O}_{8}\right)$ & 17.0 & 18.2 & 17.4 & 18.0 & 16.2 & \\
\hline
\end{tabular}

${ }^{a}$ Bond lengths are in $\AA$ and angles in degrees. ${ }^{b}$ From ref 20 for methyl azide. ${ }^{c}$ From ref 21 for azidobuthyne.

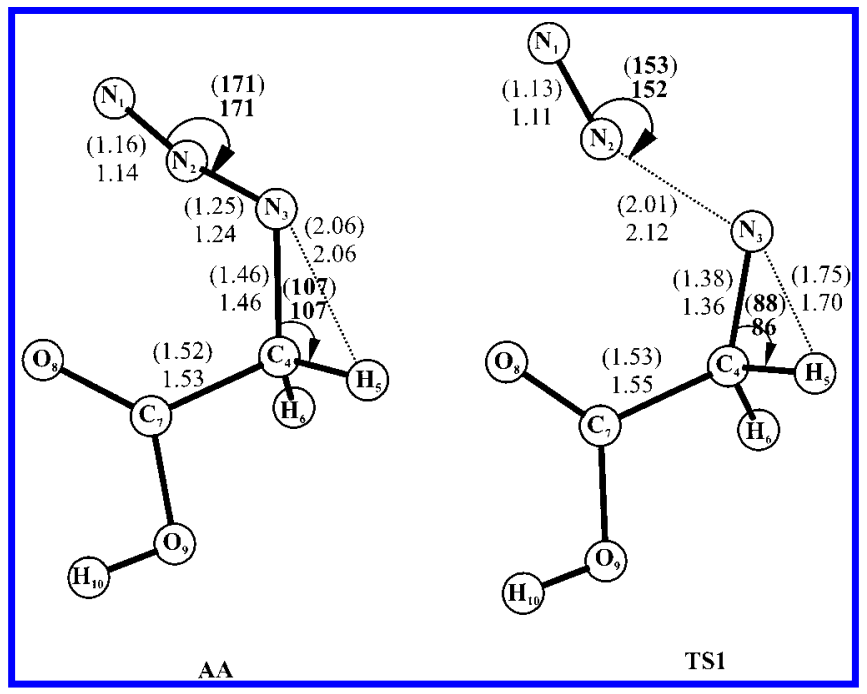

Figure 2. B3LYP/6-31G**-optimized geometries of the azidoacetic acid (AA) and the transition state (TS1) for $\mathrm{N}_{2}$ elimination (Scheme 1). Distances are in $\AA$ and angles (bold format) in degrees. MP2/6$31 \mathrm{G}^{* *}$ values are given in parentheses.

calculations using the larger $6-311 \mathrm{G}^{* *}$ basis set are not shown, as they had the same behavior as those of the MP2 method.

In general, bond lengths decrease slightly as the basis set is expanded from $6-31 \mathrm{G}^{* *}$ to $6-311 \mathrm{G}^{* *}$. However, the largest changes in bond lengths do not exceed ca. $0.01 \AA$. Changes in valence and dihedral angles are also quite small-the largest changes amount to about $1-2^{\circ}$.

DFT and MP2 geometries closely resemble each other, in particular the geometric parameters of B3LYP/6-31G** and MP2/6-311G*. HF structures show, however, some differences with respect to those predicted by the MP2 method that can be attributed to electronic correlation effects. To be noticed are its smaller NN and CO bond lengths and, especially, its larger NNN valence angle. Previous theoretical studies on other azides have also shown that electronic correlation effects tend to increase the NNN bending. ${ }^{22}$

Nevertheless, all methods give a rather similar picture overall for the optimal geometry of azidoacetic acid. They show that the molecule has a slightly distorted gauche conformation with the NNN chain skewed in relation to the CCOO moiety; the NNN chain is not linear and the two NN bonds lengths are quite different from each other.

To our knowledge there is no experimental data for the structure of azidoacetic acid. However the present results may be compared with experimental data for other azides. For instance, as shown in Table 1, the predicted bond lengths and valence angles are in good agreement with the experimental values for methyl azide and azidobuthyne.

Ionization Energies. The first nine ionization energies based on Koopmans' theorem are presented in Table 2 and compared with the most recent PE experimental data. In some cases, the adiabatic first ionization energy has been computed, and the results obtained are also reported in this table.

As expected, Koopmans' calculated ionization energies are higher than the experimental PE values, but good agreement is seen, except for the B3LYP method. In fact, DFT methods are known to strongly underestimate the ionization energies, ${ }^{22 b}$ although some improvement is reached when the B3 functional is used. The results in Table 2 also show that the Koopmans' energies do not quite depend on the basis set or on the correlation effects. In fact, even the HF/6-31G** values, when scaled by the well-known 0.9 factor, ${ }^{23}$ agree pretty well with the PE measured energies.

Adiabatic first ionization energies are also in reasonable agreement with the experimental data, the HF method being the method that gives poor results. In addition, inclusion of ZPE corrections practically does not affect the adiabatic ionization energies.

To have an idea of the atomic charges distribution of the neutral $\mathrm{N}_{3} \mathrm{CH}_{2} \mathrm{COOH}$ and its single ionized form, Mulliken population analyses were performed. The results (not shown here $^{24}$ ) were seen to depend remarkably on the basis set used and on the consideration of electronic correlation. For instance, the charge of the middle nitrogen atom of the azido chain $\left(\mathrm{N}_{2}\right)$ is decreased by $\sim 20 \%$ on going from the HF level to the MP2 level. Nevertheless, all methods predict the same charge distribution for the azido chain, i.e.: $\mathrm{N}_{1}{ }^{-}-\mathrm{N}_{2}{ }^{+}-\mathrm{N}_{3}{ }^{-}-\mathrm{X}^{+}$. Also, comparison between the atomic charges of the neutral $\mathrm{N}_{3} \mathrm{CH}_{2}-$ $\mathrm{COOH}$ and its parent ion revealed an important charge redistribution along the azido chain. But this ought to be expected, as the highest occupied molecular orbital of $\mathrm{N}_{3} \mathrm{CH}_{2}-$ $\mathrm{COOH}$ was found to be essentially a $\mathrm{p}_{\pi}$ nonbonding $\mathrm{N}_{3}$ orbital. These results mimic the ones previously obtained for other similar azides. ${ }^{22}$

Here, it should be remarked that the MP2 method predicts, in relation to the other methods, a quite different trend for the charges of the azido chain of the ion and the strength of its $\mathrm{NN}$ bonds. The $\mathrm{N}_{1}-\mathrm{N}_{2}$ bond of $\mathrm{N}_{3} \mathrm{CH}_{2} \mathrm{COOH}^{+}$, in particular, was found to be stronger than that of the neutral species and the corresponding $v(\mathrm{~N} \equiv \mathrm{N})$ frequency higher $\left(3640 \mathrm{~cm}^{-1}\right.$ vs 2365 
TABLE 2: Comparison of Experimental and Computed Vertical Ionization Energies of Azidoacetic Acid ${ }^{a}$

\begin{tabular}{|c|c|c|c|c|c|c|}
\hline \multicolumn{2}{|c|}{$\operatorname{exptl}^{b}$} & \multicolumn{5}{|c|}{$\operatorname{method}^{c}$} \\
\hline band (MO) & value & $\mathrm{HF} / 6-31 \mathrm{G}^{* *}$ & $\mathrm{HF} / 6-311 \mathrm{G}^{* *}$ & $\mathrm{MP} 2 / 6-31 \mathrm{G}^{* *}$ & $\mathrm{MP} 2 / 6-311 \mathrm{G}^{* *}$ & B3LYP/6-31G** \\
\hline $1(26)$ & 9.95 & $10.4(8.9)^{d}$ & $10.5(9.1)^{d}$ & $10.4(10.3 ; \mathbf{1 0 . 3})^{d}$ & 10.5 & $7.1(9.4 ; 9.5)^{d}$ \\
\hline $2(25)$ & 11.17 & 12.2 & 12.3 & 12.1 & 12.1 & 8.1 \\
\hline $3(24)$ & 11.79 & 13.0 & 13.0 & 13.1 & 13.1 & 8.6 \\
\hline $4(23)$ & 12.38 & 13.6 & 13.7 & 13.6 & 13.7 & 9.3 \\
\hline $5(22)$ & 14.31 & 15.9 & 15.9 & 15.9 & 15.9 & 11.3 \\
\hline $6(21)$ & 14.65 & 16.3 & 16.4 & 16.3 & 16.4 & 11.4 \\
\hline $7(20)$ & 15.16 & 17.7 & 17.8 & 17.5 & 17.6 & 12.2 \\
\hline $8(19)$ & 15.96 & 18.4 & 18.5 & 18.1 & 18.2 & 13.0 \\
\hline $9(18)$ & 17.15 & 18.7 & 18.8 & 18.5 & 18.6 & 13.3 \\
\hline
\end{tabular}

${ }^{a}$ Values in eV. ${ }^{b}$ Reference 14a. ${ }^{c}$ Ionization energies based on Koopmans' theorem. ${ }^{d}$ Computed as the difference between the ground state energies of the optimized structures of the singly ionized $\left(\mathrm{N}_{3} \mathrm{CH}_{2} \mathrm{COOH}^{+}\right)$and neutral $\left(\mathrm{N}_{3} \mathrm{CH}_{2} \mathrm{COOH}\right)$ forms of azidoacetic acid. Values in bold format include ZPE corrections.

TABLE 3: Selected Vibrational Frequencies of Azidoacetic Acid

\begin{tabular}{|c|c|c|c|c|c|}
\hline \multirow[b]{2}{*}{ assignment } & \multicolumn{5}{|c|}{ frequencies $^{a}$} \\
\hline & $\mathrm{HF} / 6-31 \mathrm{G}^{* *}$ & $\mathrm{MP} 2 / 6-31 \mathrm{G}^{* *}$ & BLYP/6-31G** & B3LYP/6-31G** & exptl \\
\hline$\delta(\mathrm{NNC})$ & 304 & 284 & 273 & 283 & $245^{b}$ \\
\hline$\tau(\mathrm{N}=\mathrm{N})$ & 657 & 547 & 532 & 570 & $564^{c}$ \\
\hline$\delta(\mathrm{NNN})$ & 799 & 740 & 696 & 727 & $657^{c}$ \\
\hline$v(\mathrm{NC})$ & 1036 & 978 & 915 & 967 & $910^{b}$ \\
\hline$\nu(\mathrm{N}=\mathrm{N})$ & 1422 & 1350 & 1293 & 1354 & $1285^{d}\left(1280^{b}\right)$ \\
\hline$v(\mathrm{C}=\mathrm{O})$ & 2021 & 1861 & 1778 & 1862 & $1742^{d}\left(1746^{e}\right)$ \\
\hline$v(\mathrm{NN})$ & 2478 & 2365 & 2156 & 2274 & $2117^{d}\left(2121^{f}\right)$ \\
\hline$v_{\mathrm{as}}(\mathrm{CH})$ & 3148 & 3115 & 2939 & 3023 & $2921^{d}$ \\
\hline$v(\mathrm{OH})$ & 4078 & 3808 & 3586 & 3750 & $3500^{d}$ \\
\hline
\end{tabular}

${ }^{a}$ Frequencies in $\mathrm{cm}^{-1} .{ }^{b}$ From ref 21 for azidoethane. ${ }^{c}$ From ref 25 for methyl azide. ${ }^{d}$ From ref 14 a for azidoacetic acid. ${ }^{e}$ From ref 26 for formaldehyde. ${ }^{f}$ From ref 1 a for azidoacetone.

$\mathrm{cm}^{-1}$ ). However, the ionization of $\mathrm{N}_{3} \mathrm{CH}_{2} \mathrm{COOH}$ was expected to result in a weaker $\mathrm{N}_{1}-\mathrm{N}_{2}$ bond and, indeed, such was the case for the calculations carried out with the B3LYP method. A likely explanation is that, at the MP2 level, the nitrogen $\mathrm{p}$ orbitals delocalize more on the ion and increase the triple $\mathrm{N}_{1}-$ $\mathrm{N}_{2}$ bond character. On the other hand, it should be stressed that some test calculations performed with a more accurate method, such as the quadratic configuration interaction method QCISD/ $6-31 G^{* *}$, showed the same trend for the strength of the NN bonds as the ones gathered from the B3LYP calculations. Taking into account these results, we believe that the MP2 method has a different behavior in predicting the strength of the $\mathrm{NN}$ bonds and frequencies that involve the NNN stretching, and in fact, this has already been pointed out by other authors. ${ }^{13 a}$

Vibrational Frequencies. Vibrational frequencies calculated for the optimized structure of azidoacetic acid are summarized in Table 3 and compared to some characteristic vibrational modes of analogous azides.

Frequencies computed at the HF level are higher than the experimental frequencies, but scaling by the usual 0.9 factor affords a much better agreement with the experimental values. MP2, BLYP, and B3LYP frequency values closely resemble each other and show an even better agreement with experimental data. Overall, DFT methods are the ones that best reproduce the experimental vibrational frequencies, particularly those concerning the torsion mode $\tau(\mathrm{N} \equiv \mathrm{N})$ and the stretching modes $v(\mathrm{NC}), v(\mathrm{~N}=\mathrm{N}), v(\mathrm{C}=\mathrm{O}), v(\mathrm{~N} \equiv \mathrm{N})$, and $v_{\text {as }}(\mathrm{CH})$.

Finally, it should be said that all of the above results and comparisons suggested that DFT methods using the 6-31G** basis set were, as a compromise between computational speed and accuracy, the best choice for the present study. Considering that and taking into account other theoretical work on similar azide reactions, ${ }^{6 \mathrm{~d}, 13 \mathrm{a}}$ the present study mostly relies on the less demanding B3LYP/6-31G** method.
SCHEME 1. Multistep Process

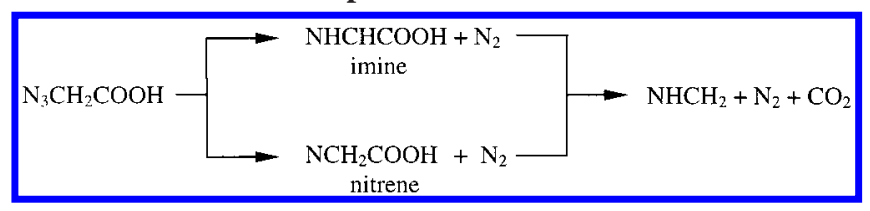

Mechanisms for the Pyrolysis of Azidoacetic Acid

Initial Decomposition of $\mathbf{N}_{\mathbf{3}} \mathbf{C H}_{\mathbf{2}} \mathbf{C O O H}$. To study the pyrolysis of the azidoacetic acid according to the multistep reactions of Scheme 1, B3LYP/6-31G** calculations have been performed starting from the optimized geometry of this acid (Figure 2). A potential energy surface (PES) was generated by assigning fixed values to the coordinates $r\left(\mathrm{~N}_{2}-\mathrm{N}_{3}\right)$ and $\angle\left(\mathrm{N}_{3}-\right.$ $\mathrm{C}_{4}-\mathrm{H}_{5}$ ) and optimizing all other coordinates.

On the singlet PES a transition state was localized that connects the acid $\mathrm{N}_{3} \mathrm{CH}_{2} \mathrm{COOH}$ with the imine $\mathrm{NHCHCOOH}$ and $\mathrm{N}_{2}$. The geometry of this transition state optimized at the B3LYP/6-31G** and MP2/6-31G** levels (TS1) is displayed in Figure 2. By comparing TS1 with the reactant (AA), it may be seen that it has a much shorter $\mathrm{N}_{3}-\mathrm{H}_{5}$ distance $(1.70 \AA$ vs $2.06 \AA$ ), a much larger $\mathrm{N}_{2}-\mathrm{N}_{3}$ bond length (2.12 $\AA$ vs $1.24 \AA$ ), and a decreased $\angle\left(\mathrm{N}_{3}-\mathrm{C}_{4}-\mathrm{H}_{5}\right)$ bond angle $\left(86^{\circ}\right.$ vs $\left.107^{\circ}\right)$. This clearly indicates that $\mathrm{H}_{5}$ transfer from $\mathrm{C}_{4}$ to $\mathrm{N}_{3}$ and breaking of the $\mathrm{N}_{2}-\mathrm{N}_{3}$ bond are taking place concertedly. A IRC calculation beginning at the TS1 transition state confirmed that, when the forward direction is followed, the $\mathrm{H}_{5}$ atom is in fact being transferred to the $\mathrm{N}_{3}$ atom, and thus, the ending products are $\mathrm{NHCHCOOH}$ and $\mathrm{N}_{2}$.

The normal vibrational mode that corresponds to the imaginary frequency of TS1 is mainly related to the stretching of the $\mathrm{N}_{2}-\mathrm{N}_{3}$ bond that is breaking. Also, in agreement with other similar reaction studies on methyl azide, ${ }^{13 \mathrm{a}}$ a substantial decrease in the torsion $\tau(\mathrm{N}=\mathrm{N})$ and bending $\delta(\mathrm{NNN})$ modes and a great increase in the stretching $v(\mathrm{~N} \equiv \mathrm{N})$ mode are observed. 


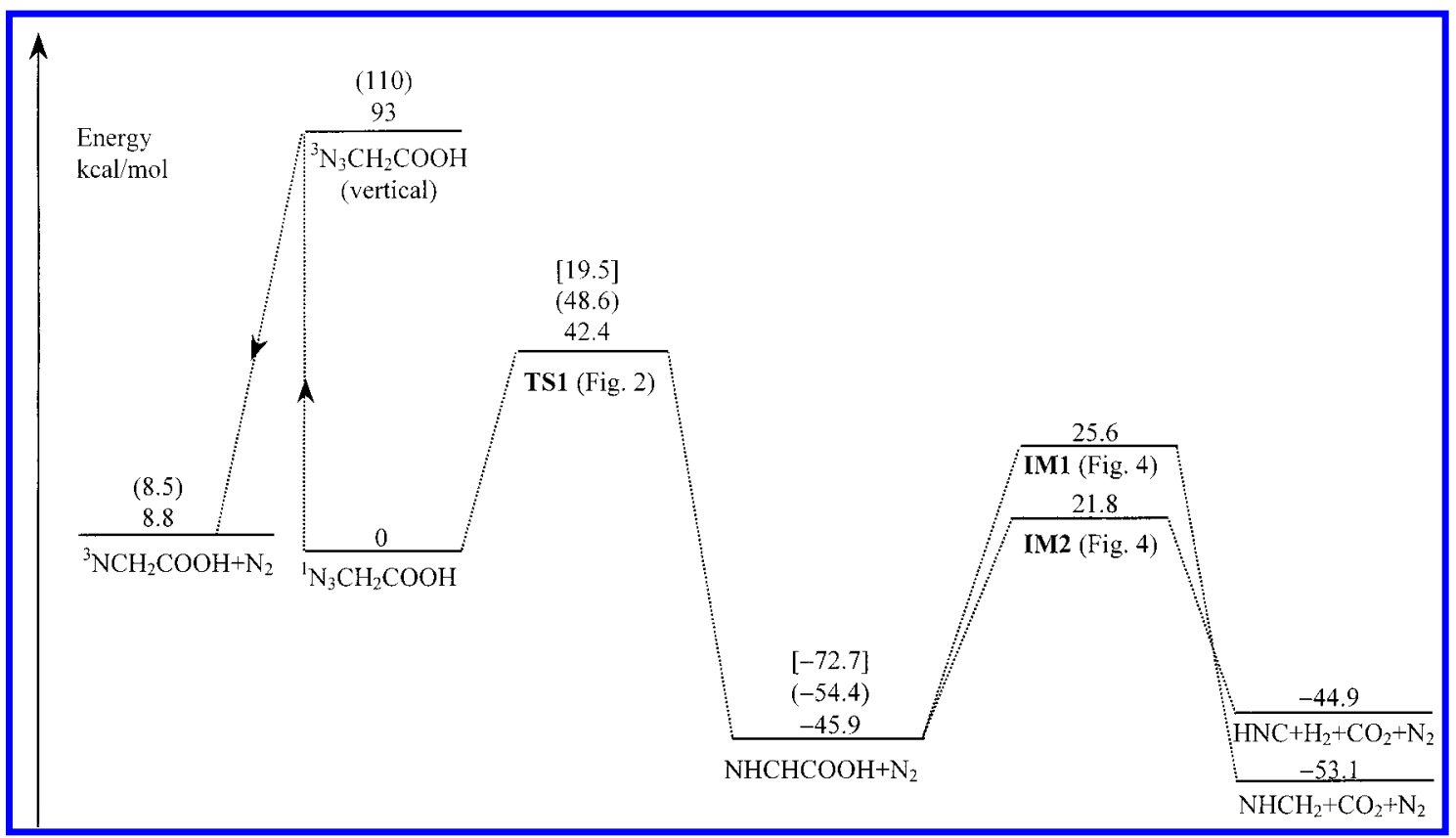

Figure 3. Relative energies (in $\mathrm{kcal} / \mathrm{mol}$ ) for the pyrolysis of azidoacetic acid following Scheme 1 . Energies include ZPE corrections and are derived from B3LYP/6-31G** calculations. HF/6-31G** (in brackets) and MP2/6-31G** (in parentheses) values are also shown in some cases.

Relative energies for all the species that might be involved on this stepwise process are shown in Figure 3. Formation of imine is exothermic and requires a high activation energy. The vertical triplet excited state of azidoacetic acid lies 90-100 kcal/ mol above its ground state and is not a true stationary point as, when relaxed, ejection of $\mathrm{N}_{2}$ proceeds without any energy barrier. These results are analogous to the results previously obtained for the decomposition of simpler alkyl azides, using similar DFT and MP2 methods. ${ }^{12,13 a}$

One should also notice the clearly poor performance of the HF method for describing this reaction (cf. Figure 3).

It should be emphasized here that systematic scans of the system's PES showed that no transition state corresponding to the formation of the nitrene $\mathrm{NCH}_{2} \mathrm{COOH}$ exists for either the B3LYP or the MP2 method. In fact, all geometry optimizations performed with (singlet) nitrene-like structures always converged to the structure of TS1.

The nitrene $\mathrm{NCH}_{2} \mathrm{COOH}$ has a triplet ground state, and full optimization of its geometry has been successfully attained with the present methods. Using the B3LYP method, we were also able to locate a stationary point of $C_{\mathrm{s}}$ symmetry for the singlet excited nitrene state, lying ca. $43 \mathrm{kcal} / \mathrm{mol}$ above the triplet state (Notice that Travers et al. ${ }^{11}$ found a value of ca. $31.2 \pm 0.25$ $\mathrm{kcal} / \mathrm{mol}$ for the triplet/singlet splitting of methyl azide.). However, by checking the analytical force constants we found that it did not correspond to a genuine stationary point. And again, upon relaxing any geometry constrains, it optimizes to the imine $\mathrm{NHCHCOOH}$. This leads us to conclude that more advanced methods would be required to achieve precisely the minimum energy structure of the singlet nitrene. Identical conclusions have already been pointed out for other theoretical studies of azides. ${ }^{10 \mathrm{~d}, 13 \mathrm{~b}, 27}$

Recently, Arenas et al., ${ }^{13 b}$ using multiconfigurational ab initio (MC-SCF) methods, have found that the rate-limiting step of the decomposition of methyl azide is a nonconcerted process that produces methylnitrene and $\mathrm{N}_{2}$. Spin-allowed and spinforbidden paths for this process were found to be isoenergetic, thereby being competitive. No evidence for a concerted $\mathrm{N}_{2}$ splitoff and $\mathrm{H}$ shift from $\mathrm{C}$ to $\mathrm{N}$, i.e. a process similar to the one observed here, has been found by that group.
They have also concluded that both MP2 and DFT methods are unable to locate the singlet methylnitrene, since this lowest (closed-shell) state of methylnitrene must be described by a twoconfiguration model. It thus seems worthwhile to perform MCSCF calculations for the closed-shell and open-shell excited singlet states of $\mathrm{NCH}_{2} \mathrm{COOH}$ nitrene, as well as for its triplet ground state, to discuss their relative stability and possible interplay in the $\mathrm{N}_{3} \mathrm{CH}_{2} \mathrm{COOH}$ pyrolysis.

The MC-SCF calculations were performed within the complete active space self-consistent field (CAS-SCF) method, using the $6-31 \mathrm{G}^{* *}$ basis set. The active space chosen comprises the $\mathrm{NCH}_{2} \mathrm{COOH}$ molecular orbitals with the greatest contribution from the in-plane and out-plane $2 p$ orbitals on nitrogen atom, thus including three orbitals and four electrons.

Starting from the singlet B3LYP/6-31G** minimum found for $\mathrm{NCH}_{2} \mathrm{COOH}\left(C_{\mathrm{s}}\right.$ symmetry), full geometry optimizations enabled us to locate the closed-shell singlet $\left({ }^{1} \mathrm{~A}^{\prime}\right.$ symmetry $)$ and the open-shell singlet $\left({ }^{1} \mathrm{~A}^{\prime \prime}\right.$ symmetry) nitrene states. Closedsell ${ }^{1} \mathrm{~A}^{\prime}$ rather than the open-shell ${ }^{1} \mathrm{~A}^{\prime \prime}$ was found to be the lowest excited state of nitrene. However, the energy difference between the two states is predicted to be very small $\left[\Delta E\left({ }^{1} \mathrm{~A}^{\prime} \angle{ }^{1} \mathrm{~A}^{\prime \prime}\right)=\right.$ $0.73 \mathrm{kcal} / \mathrm{mol}$ ]. Full optimization of the triplet ground state of nitrene at this level of theory showed us that the triplet state lies about $40 \mathrm{kcal} / \mathrm{mol}$ below the ${ }^{1} \mathrm{~A}^{\prime}$ state.

It is possible that the lowest (closed-shell) singlet state of $\mathrm{NCH}_{2} \mathrm{COOH}$ will take part in the pyrolysis of $\mathrm{N}_{3} \mathrm{CH}_{2} \mathrm{COOH}$, just as suggested by Arenas et al. ${ }^{13 \mathrm{~b}}$ in the case of the pyrolysis of methyl azide. They ${ }^{13 \mathrm{~b}}$ have also checked that the conversion between methylnitrene and methanimine is practically a barrierfree process. Accordingly to them that is the reason methanimine is the only observed product of the pyrolysis of methyl azide. Similarly, for the present pyrolysis, the singlet nitrene $\mathrm{NCH}_{2}-$ $\mathrm{COOH}$ intermediate should rapidly isomerize into the imine $\mathrm{NHCHCOOH}$. Thus, although the singlet or the triplet nitrene may be difficult to observe experimentally, there is no reason for not detecting the imine $\mathrm{NHCHCOOH}$. Nevertheless, further work on the reactions of this scheme is certainly needed and will be deferred for a latter study.

Decomposition of NHCHCOOH. No evidence that could possibly be associated with the imine $\mathrm{NHCHCOOH}$ was 
TABLE 4: Some Geometrical Parameters and Vibrational Frequencies Computed for the Imine NHCHOOH in Comparison with the Acid $\mathrm{N}_{3} \mathrm{CH}_{2} \mathrm{COOH}^{a}$

\begin{tabular}{llcccr}
\hline coordinate $^{b}$ & $\mathrm{NHCOOH}$ & $\mathrm{N}_{3} \mathrm{CH}_{2} \mathrm{COOH}$ & frequenciesc & $\mathrm{NHCOOH}^{2}$ & $\mathrm{~N}_{3} \mathrm{CH}_{2} \mathrm{COOH}^{-}$ \\
\hline$r(\mathrm{NC})$ & $1.269\left(1.270^{d}\right)$ & 1.460 & $v(\mathrm{CN})$ & $1726\left(1712^{d}\right)$ & 967 \\
$r(\mathrm{C}=\mathrm{O})$ & 1.212 & 1.207 & $v(\mathrm{CO})$ & 1838 & 1862 \\
$(\mathrm{NCC}=\mathrm{O})$ & 0.0 & 16.2 & & &
\end{tabular}

${ }^{a}$ Computed at the B3LYP/6-31G** level. ${ }^{b}$ Bond lengths in $\AA$ and angles in degrees. ${ }^{c}$ Frequencies in $\mathrm{cm}^{-1} .{ }^{d}$ Computed for methanimine.

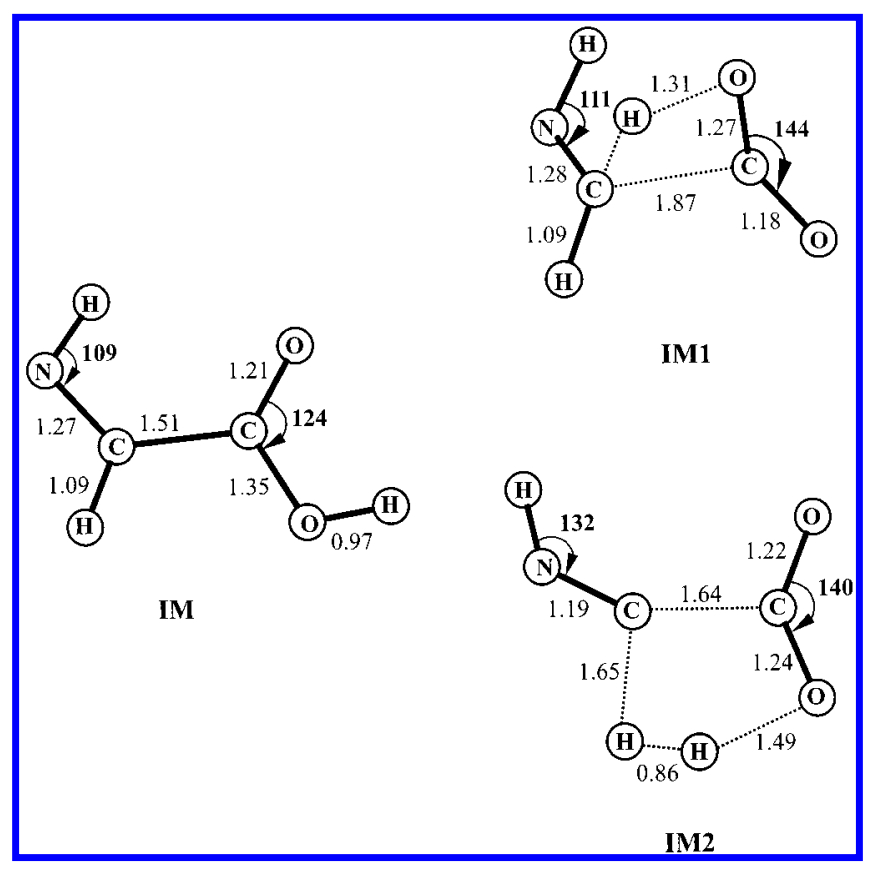

Figure 4. B3LYP/6-31G**-optimized geometries for the dissociation of the imine NHCHCOOH: IM, ground-state $\mathrm{NHCHCOOH}$ imine; IM1, transition state for the dissociation into $\mathrm{NHCH}_{2}$ and $\mathrm{CO}_{2}$; IM2, transition state for the dissociation into $\mathrm{HNC}, \mathrm{CO}_{2}$, and $\mathrm{H}_{2}$. Distances are in $\AA$ and angles (bold format) in degrees.

observed upon the pyrolysis of azidoacetic acid. ${ }^{14 a}$ Nevertheless, some of the possible mechanisms for the thermal decomposition of this imine will be discussed here.

$\mathrm{NHCHCOOH}$ has a singlet ground state and is predicted to be planar with $C_{\mathrm{s}}$ symmetry (cf. Figure 4 ). Some geometrical parameters and vibrational frequencies of this molecule are given in Table 4 and compared with the ones obtained for the azidoacetic acid. Worth mentioning is the increase on the $v$ (CN) stretching frequency that is consistent with a shorter $\mathrm{CN}$ double bond similar to the one of methanimine.

Starting from $\mathrm{NHCHCOOH}$, there are certainly innumerous reaction pathways that might lead to the experimentally observed products (i.e.: $\mathrm{NHCH}_{2}, \mathrm{CO}_{2}, \mathrm{HCN}$, and probably $\mathrm{H}_{2}{ }^{14 \mathrm{a}}$ ). The study of the entire network of possible reactions is, however, behind the scope of this work. After some searches we have located two interesting transitions states that are shown in Figure 4. The first transition state (IM1) connects $\mathrm{NHCHOOH}$ with $\mathrm{NHCH}_{2}+\mathrm{CO}_{2}$ and the second one (IM2) with $\mathrm{HNC}+\mathrm{CO}_{2}+$ $\mathrm{H}_{2}$, as confirmed by the IRC calculations. The relative energies for the species involved on both reaction pathways are shown in Figure 3.

IM1 has a nonplanar ring structure reflecting a great twisting of the imine equilibrium geometry (IM). In this structure, the $\mathrm{C}-\mathrm{H}$ bond to produce methanimine is partially formed $(1.38$ $\AA)$, whereas the $\mathrm{O}-\mathrm{H}$ bond $(1.31 \AA)$ and the $\mathrm{CC}$ bond $(1.87$ $\AA)$ are essentially broken. Also, the $\angle(\mathrm{HCN})$ angle is identical to that of $\mathrm{NHCH}_{2}$, but the $\mathrm{COO}$ angle is still bent.

The products of the reaction via IM1 lie only a few kcal/ mol below the reactant $\mathbf{I M}$, and hence, this reaction is much less exothermic than the $\mathrm{N}_{2}$ loss reaction already discussed.
SCHEME 2. Concerted Process

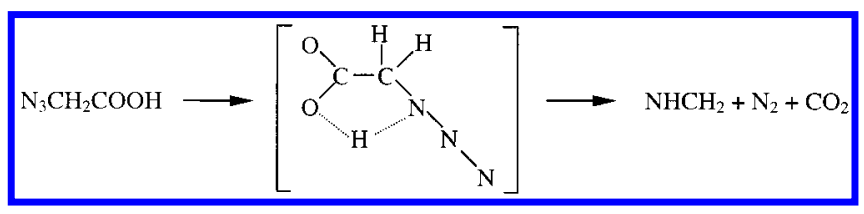

However, the height of its barrier is almost double the one of that reaction $(71.5 \mathrm{kcal} / \mathrm{mol}$ vs $42.4 \mathrm{kcal} / \mathrm{mol})$. Again, this energetic data does not provide an answer to the question of why the imine $\mathrm{NHCHCOOH}$ is not detected.

The most striking geometrical feature of IM2 is its resemblance to the common transition state proposed for the $1,1-\mathrm{H}_{2}$ dehydrogenation of $\mathrm{NHCH}_{2}$. As emphasized recently, ${ }^{12,13 \mathrm{~b}}$ starting from $\mathrm{NHCH}_{2}, 1,2-\mathrm{H}_{2}$ loss giving $\mathrm{HCN}$ is less favored than the $1,1-\mathrm{H}_{2}$ loss giving $\mathrm{HNC}$, followed by a fast isomerization of the unstable HNC to HCN. Similarly, in our case, concerted $\mathrm{H}_{2}$ and $\mathrm{CO}_{2}$ elimination from $\mathrm{NHCHCOOH}$ (IM2) to produce $\mathrm{HNC}$ is predicted to be more favorable than simply $\mathrm{CO}_{2}$ elimination (IM1). Taking into account that $\mathrm{HNC}$ formation via the IM2 transition state is slightly endothermic, HNC rearrangement to $\mathrm{HCN}$ is also expected.

Finally, it should be said that other possibilities for the dissociation of the imine $\mathrm{NHCHCOOH}$ have been looked for, such as its rearrangement to an aminocarbene-like structure, but they were all found to be useless to the present study. ${ }^{24}$

To study the pyrolysis of $\mathrm{N}_{3} \mathrm{CH}_{2} \mathrm{COOH}$ according to the concerted mechanism shown in Scheme 2, the system's PES was scanned in several directions. No transition state for the one-step process could be found from the several performed scans and geometry optimizations. This suggested to us that the azidoacetic acid probably does not dissociate directly into the desired $\mathrm{NHCH}_{2}, \mathrm{CO}_{2}$, and $\mathrm{N}_{2}$ products. Furthermore, the optimized geometry of $\mathrm{N}_{3} \mathrm{CH}_{2} \mathrm{COOH}$ (see Figure 2) might not be an adequate starting point to follow this scheme.

As mentioned before, the transition state proposed has a fivemembered ring structure to allow for the simultaneous ejection of $\mathrm{N}_{2}$ and $\mathrm{CO}_{2}{ }^{14 \mathrm{a}}$. However, formation of this kind of ring requires the $\mathrm{OH}$ bond to be in a cis configuration with respect to the NNN chain. In this sense, the most adequate starting geometry is not the minimum gauche conformer of $\mathrm{N}_{3} \mathrm{CH}_{2-}$ $\mathrm{COOH}\left(\phi \approx 60^{\circ}\right)$ but its anti conformer $\left(\phi=180^{\circ}\right)$. Taking into account the low-energy barrier for the gauche-anti conversion (ca. $1.8 \mathrm{kcal} / \mathrm{mol}$ ), the anti conformer should represent a plausible starting structure. Again, systematic scans of the PES of this latter system did not lead to the proposed TS ring or other appropriate TS.

Although in the anti conformer the $\mathrm{OH}$ bond is in a good position in relation to the NNN chain, the $\mathrm{H}$ atom is not directed toward that chain, thus making rather difficult the simultaneously detachment of this atom from oxygen and bonding to the target nitrogen. Therefore, an additional scan for the rotation of the $\mathrm{OH}$ bond was done to assess its energy barrier and to check if this new structure corresponds to a stationary point. The PES scan for the $\mathrm{OH}$ rotation was obtained by fixing the $\mathrm{CCOH}$ dihedral angle and optimizing all others coordinates. In this way, a barrier of about $12.8 \mathrm{kcal} / \mathrm{mol}$ was found for this rotation. 


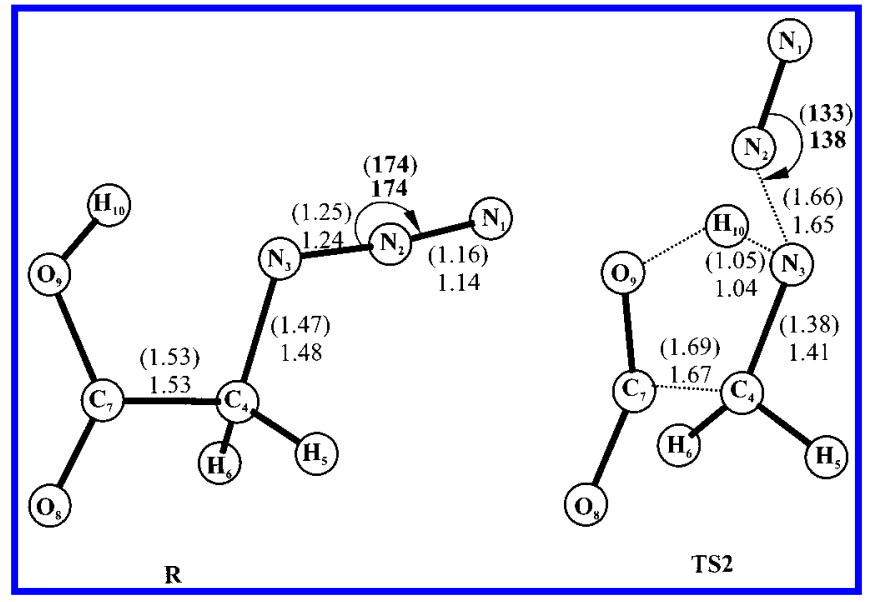

Figure 5. B3LYP/6-31G**-optimized geometries for the initial reactant of azidoacetic acid (R) and the transition state (TS2) of the pyrolysis of azidoacetic acid following Scheme 2. Distances are in $\AA$ and angles (bold format) in degrees. MP2/6-31G** values are given in parentheses.

The calculations showed also that this distorted anti structure is in fact a minimum lying about $2 \mathrm{kcal} / \mathrm{mol}$ above the anti conformer. From now on this stationary point will be designated as $\mathbf{R}$.

A new scan on the potential energy surface allowed us to detect a transition state that connects the reactant $\mathbf{R}$ with the desired products, as then confirmed by IRC calculations. Figure 5 shows the geometry of the initial reactant $(\mathbf{R})$ and the transition state structure (TS2) optimized at the B3LYP/6-31G** level. The optimized MP2/6-31G** values are also given.

As can be seen in this figure, TS2 has a strained fivemembered ring and its structure closely resembles the products of the reaction. For example, the $\mathrm{N}_{2}-\mathrm{N}_{3}$ and $\mathrm{O}_{9}-\mathrm{H}_{10}$ bonds are virtually broken, whereas the $r\left(\mathrm{~N}_{3}-\mathrm{H}_{10}\right)$ is already formed. It can be also noticed that the $\mathrm{C}_{4}-\mathrm{C}_{7}$ bond is partially disrupted and the $\angle \mathrm{N}_{1} \mathrm{~N}_{2} \mathrm{~N}_{3}$ angle is much more bent than that of the reactant $\mathbf{R}$.
The normal mode corresponding to the imaginary vibrational frequency of this transition state consists mainly of stretching of the bonds that are breaking and forming. As expected, the torsion $\tau(\mathrm{N}=\mathrm{N})$ and the bending $\delta(\mathrm{NNN})$ modes decrease and the stretching $v(\mathrm{~N} \equiv \mathrm{N})$ mode increases with respect to the corresponding modes of the $\mathbf{R}$ optimized structure. Particularly noteworthy, however, is that the stretching $v(\mathrm{OH})$ mode of the reactant is transformed into a stretching $v(\mathrm{NH})$ mode in the TS2 structure. This is clearly due to the disruption of the $\mathrm{OH}$ bond and strengthening of the NH bond in the TS2 structure.

The relative energies of the reactants, products, intermediates, and transition state for this reaction are compared in Figure 6.

Figure 6 shows that this dissociation scheme is, as expected, quite exothermic and is slightly favored in relation to the $\mathrm{N}_{2}$ elimination step of Scheme 1 (see Figure 3). In addition, the products of the complete dissociation of the azidoacetic acid (Scheme 2) are estimated to be $7 \mathrm{kcal} / \mathrm{mol}$ below the products $\mathrm{NHCHOOH}$ and $\mathrm{N}_{2}$ (Scheme 1). Although these products have a similar stability, interconversion between them requires substantial activation energy, according to the predictions of the last section.

For all reactions studied, the biggest change in the relative energies of stationary points on going from the B3LYP to the MP2 method amounts to $9 \mathrm{kcal} / \mathrm{mol}$, deviations being larger for minima than for transition states. However, similar trends are observed for activation energies and relative stabilities.

At this point its is important to establish the main conclusions of this study. The concerted reaction suggested for the decomposition of azidoacetic acid into $\mathrm{NHCH}_{2}, \mathrm{CO}_{2}$, and $\mathrm{N}_{2}$ appears to be unreachable without a previous distortion of the equilibrium geometry of $\mathrm{N}_{3} \mathrm{CH}_{2} \mathrm{COOH}$ (gauche conformer). Instead, we believe that it first converts to the anti conformer, which then transforms to the $\mathbf{R}$ conformer, and finally dissociates into $\mathrm{NHCH}_{2}, \mathrm{CO}_{2}$, and $\mathrm{N}_{2}$. However, judging from the predicted activation energies, the successive conformers (gauche $\leftrightarrow$ anti $\leftrightarrow \mathbf{R})$ convert into one another easily, and thus, they may coexist

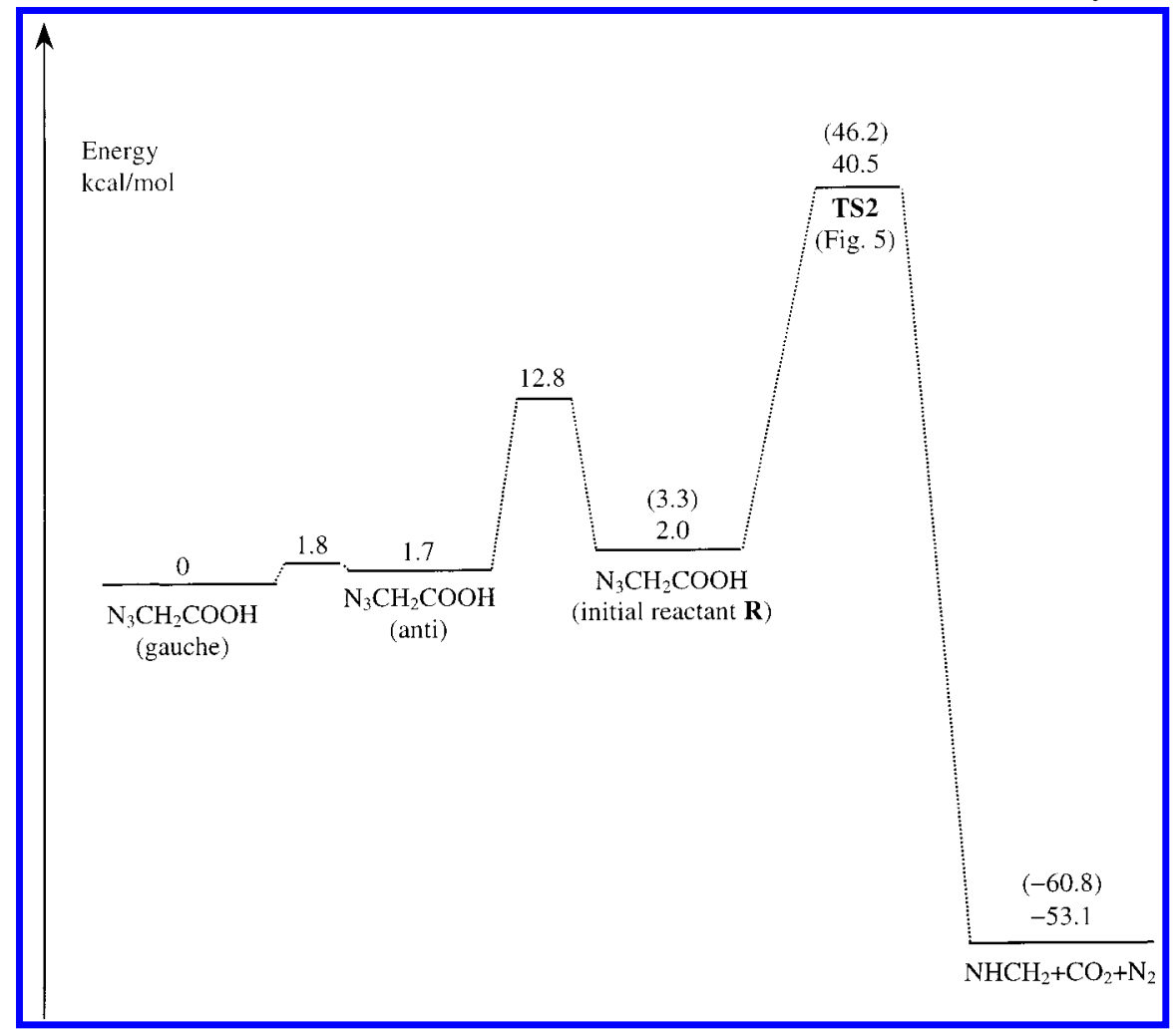

Figure 6. Relative energies (in $\mathrm{kcal} / \mathrm{mol}$ ) for the pyrolysis of azidoacetic acid following Scheme 2. Energies include ZPE corrections and are derived from $\mathrm{B} 3 \mathrm{LYP} / 6-31 \mathrm{G}^{* *}$ or $\mathrm{MP} 2 / 6-31 \mathrm{G}^{* *}$ (values in parentheses) calculations. 
at room temperature. Moreover, they certainly do coexist at the temperature under which the pyrolysis experiments are conducted. On the other hand, the rate-limiting step of this mechanism is the dissociation of $\mathbf{R}$ via a ring transition state structure, thus confirming the experimental predictions. ${ }^{14 a}$ It is most likely that the barrier of this concerted reaction will be change at higher level ab initio calculations. In fact, as already pointed out by several groups, ${ }^{6 \mathrm{~d}}$ the B3LYP method properly describes the structure of this class of molecules but usually underestimates reaction barriers. The MP2 method, on the other hand, seems to be less reliable than the B3LYP method. ${ }^{6 \mathrm{~d}, 13 \mathrm{a}}$ However, although there is no experimental activation energy for the present reaction to be compared with, we believe that the present results are not significantly affected by the shortcomings of both methods. Therefore, the concerted reaction via the ring TS2 structure is predicted to be the most reasonable mechanism for the pyrolysis of azidoacetic acid. One might argue, however, that other stepwise reaction schemes (e.g., involving the nitrene intermediate) may exist and have isoenergetic competitive rate-limiting steps, but Scheme 2 is the only one that can cope with the experimental findings.

\section{Summary and Conclusions}

The present study reports several ab initio and DFT calculations on the molecular properties of azidoacetic acid. Consideration of electronic correlation effects is found to be essential to have a reliable theoretical description of the properties of this acid. Overall, DFT results for the structure, ionization energies, and vibrational frequencies of the azidoacetic acid are, normally, in better agreement with experimental data than those predicted by MP2 calculations.

The mechanism for the gas-phase pyrolysis of azidoacetic was investigated by resorting to the B3LYP and MP2 methods. Two types of mechanisms were considered: one involving multistep reactions and producing the nitrene $\mathrm{NCH}_{2} \mathrm{COOH}$ or the imine $\mathrm{NHCHCOOH}$ as intermediates and the other being a concerted one that yields directly the observed products $\left(\mathrm{N}_{2}\right.$, $\mathrm{CO}_{2}$, and $\mathrm{NHCH}_{2}$ ). In agreement with recent experimental work, both methods predict that the pyrolysis of $\mathrm{N}_{3} \mathrm{CH}_{2} \mathrm{COOH}$ proceeds, after an initial distortion of the minimum geometry of this acid, via a concerted process involving a five-membered ring transition state that then produces $\mathrm{N}_{2}, \mathrm{CO}_{2}$, and $\mathrm{NHCH}_{2}$.

The decomposition of the imine $\mathrm{NHCHCOOH}$ has also been studied using the B3LYP method. Starting from $\mathrm{NHCHCOOH}$, concerted $\mathrm{H}_{2}$ and $\mathrm{CO}_{2}$ elimination to produce $\mathrm{HNC}$ is predicted to be more favorable than simply $\mathrm{CO}_{2}$ elimination yielding methanimine. The product HNC probably suffers rapid isomerization to $\mathrm{HCN}$.

This study is, however, limited to the description of the lowest singlet potential energy surface of the azidoacetic acid and relies mostly on the B3LYP method. Thus, further work is in progress to confirm the predictions of this work and to study other possible reaction mechanisms for the gas-phase pyrolysis of azidoacetic acid.

Acknowledgment. Computer time on the ORIGIN 200 SGI of the Secção de Química Teórica do Departamento de Química (FCUP) is kindly acknowledged. This study is part of a general EU Twinning Science Plan (ERBS CI* CT000678) on "Spectroscopic studies of materials under hostile environments". We thank Elsa S. Hemriques for her invaluable suggestions.

\section{References and Notes}

(1) (a) Patai, S. The Chemistry of the Azido Group, Interscience Publishers: New York, 1971. (b) Scriven, E. F. V.; Turnbull, K. Chem.
Rev. 1988, 88, 298. (c) Vantinh, D.; Stadlbauer, W. J. Heterocycl. Chem 1996, 33, 1025. (d) Zaragoza, F.; Petersen, S. V. Tetrahedron 1996, 52, 10823.

(2) (a) Jönsson, B. M.; Håkansson, K.; Liljas, A. FEBS Lett. 1993 , 332, 186. (b) Maurus, R.; Bogumil, R.; Nguyen, N. T.; Mauk, A. G.; Brayer, G. Biochem. J. 1998, 332, 67.

(3) (a) Mijer, E. W.; Nijhuis, S.; Van Vroonhoven, F. C. B. M. J. Am. Chem. Soc. 1988, 110, 7209. (b) Schuster, G. B.; Platz, M. S. Adv. Photochem. 1992, 17, 69.

(4) (a) Bu, Y.; Chu, J. C. S.; Lin, M. C. Surf. Sci. Lett. 1992, 264 L15111. (b) Bridges, A. S.; Greef, R.; Jonathan, N. B. H.; Morris, A.; Parker, G. J. Surf. Rev. Lett. 1994, 1, 573. (c) Tindall, C.; Hemminger, J. Surf. Sci. 1995, 330, 67 .

(5) (a) Farber, M.; Harris, S. P. Srisvastava Combust. Flame 1984, 55, 203. (b) Kubota, N. J. Propul. Power 1995, 11, 677. (c) Liu, Y.-L., Hsiue, G.-H.; Chiu, Y.-S. J. Appl. Polvm. Sci. 1995, 58, 579.

(6) (a) Albini, A.; Bettinetta, G.; Minoli, G. J. Am. Chem. Soc. 1991, 113, 6928; 1997, 119, 7308. (b) Marcinek, A.; Levya, E.; Whitt, D.; Platz, M. S. J. Am. Chem. Soc. 1993, 115, 8609. (c) Karney, W. L.; Borden, W. T. J. Am. Chem. Soc. 1997, 119, 1378; 1997, 119, 33347. (d) Rauhut, G. Eckert, F. J. Phys. Chem. A 1999, 103, 9086 and references therein.

(7) (a) Currie, C. L.; Darwent, B. DeB. Can. J. Chem. 1963, 41, 1152. (b) O'Dell, M. S.; Darwent, B. DeB. Can. J. Chem. 1970, 48, 1140.

(8) (a) Bock, H.; Dammel R. Angew. Chem., Int. Ed. Engl. 1987, 26, 504. (b) Bock, H.; Dammel, R. J. Am. Chem. Soc. 1988, 110, 5261.

(9) (a) Milligan, D. E. J. Chem. Phys. 1961, 35, 1491. (b) Jacox, M. E.; Milligan, D. E. J. Mol. Spectrosc. 1975, 56, 333.

(10) (a) Demuynck, J.; Fox, D. J.; Yamagushi, Y.; Schaefer, H. F. J. Am. Chem. Soc. 1980, 102, 6204. (b) Pople, J. A.; Raghavachari, K.; Frisch, M. J.; Binkley, J. S.; Schleyer, P. v. R. J. Am. Chem. Soc. 1983, 105, 6389. (c) Nguyen, M. T. Chem. Phys. Lett. 1985, 117, 290. (d) Richards, C.; Meredith, C.; Kim, S.-K.; Quelch., G. E.; Schaefer, H. F., III J. Chem. Phys. 1994, 100, 481. (e) Sumathi, R. J. Mol. Struct. (THEOCHEM) 1996, 364, 97.

(11) Travers, M. J.; Cowels, D. C.; Clifford, E. P.; Ellison, G. B.; Engelking, P. C. J. Chem. Phys. 1999, 111, 5349. 6499.

(12) Nguyen, M. T.; Sengupta D.; Ha, T.-K. J. Phys. Chem. 1996, 100 ,

(13) (a) Arenas, J. F.; Otero, J. C.; Sánchez-Gálvez, A.; Soto, J.; Viruela, P. J. Phys. Chem. A 1998, 102, 1146. (b) Arenas, J. F.; Marcos, J. I.; Otero, J. C.; Sánchez-Gálvez, A.; Soto, J. J. Chem. Phys. 1999, 111, 551.

(14) (a) Dyke, J. M.; Groves, A. P.; Morris, A.; Ogden, J. S.; Dias, A. A.; Oliveira, A. M. S.; Costa, M. L.; Barros, M. T.; Cabral, M. H.; Moutinho, A. M. C. J. Am. Chem. Soc. 1997, 119, 6883. (b) Dyke, J. M.; Groves, A. P.; Morris, A.; Ogden, J. S.; Catarino, M. I.; Dias, A. A.; Oliveira, A. M. S.; Costa, M. L.; Barros, M. T.; Cabral, M. H.; Moutinho, A. M. C. J. Phys. Chem. A 1999, 103, 8239.

(15) Lee, C.; Yang; W.; Parr, R. G. Phys. Rev. B 1988, 37, 785.

(16) Becke, A. D. Phys. Rev. A 1988, 38, 3098.

(17) Becke, A. D. J. Chem. Phys. 1993, 98, 1372.

(18) (a) Gonzalez, C.; Schlegel, H. B. J. Chem. Phvs. 1989, 90, 2154. (b) Gonzalez, C.; Schlegel, H. B. J. Phys. Chem. 1990, 94, 5523.

(19) Frisch, M. J.; Trucks, G. W.; Schlegel, H. B.; Scuseria, G. E.; Robb, M. A.; Cheeseman, J. R.; Zakreswki, V. G.; Montgomery, J. A., Jr.; Stratmann, R. E.; Burant, J. C.; Dapprich, S.; Millam, J. M.; Daniels, A. D.; Kudin, K. N.; Strain, M. C.; Farkas, O.; Tomasi, J.; Barone, V.; Cossi, M.; Cammi, R.; Mennucci, B.; Pomelli, C.; Adamo, C.; Clifford, S.; Ochterski, J.; Petersson, G. A.; Ayala, P. Y.; Cui, Q.; Morokuma, K.; Malick, D. K.; Rabuk, A. D.; Raghavachari, K.; Foresman, J. B.; Cioslowki, J.; Ortiz, J. V.; Stefanov, B. B.; Liu, G.; Liashenko, A.; Piskorz, P.; Komaromi, I.; Gomperts, R.; Martin, R. L.; Fox, D. J.; Keith T.; Al-Laham, M. A.; Peng, C. Y.; Nanayakkara, A.; Gonzalez, C.; Challacombe, M.; Gill, P. M. W.; Johnson, B. G.; Chen, W.; Wong, M. W.; Andres, J. L.; Gonzalez, C.; Head-Gordon, M.; Replogle, E. S.; Pople, J. A. Gaussian 98, Revision A.3; Gaussian Inc.; Pittsburgh, PA, 1998.

(20) Heineking, N.; Gerry, M. C. L. Z. Naturforsch. 1989, 44a, 669.

(21) Nielsen, C. J.; Priebe, H.; Salzer, R. J. Mol. Struct. (THEOCHEM) 1987, 162, 41.

(22) (a) Cabral, B. J. C.; Costa, M. L. J. Mol. Struct. (THEOCHEM) 1995, 343, 31. (b) Catarino, M. I.; Cabral, B. J. C.; Costa, M. L. J. Mol. Struct. (THEOCHEM) 1997, 397, 223.

(23) (a) Bash, H.; Robin, M. B.; Kuebler, N. A.; Baker, C.; Turner, D. W. J. Chem. Phys. 1969, 51, 52. (b) Robin, M. B.; Brundle, C. R.; Kuebler, N. A.; Ellison, G. B.; Wilberg, K. B. J. Chem. Phvs. 1972, 57, 1758. (c) Wilberg, K. B.; Ellison, G. B.; Wendolski, J. J.; Brundle, C. R.; Kuebler, N. A. J. Chem. Phys. 1976, 98, 7179.

(24) Dias, A. A. MSc. Thesis, Universidade Lisboa, Lisboa, 1999.

(25) Nielsen, C. J.; Sjogren, C. E. J. Mol. Struct. (THEOCHEM) 1987, 150,361 .

(26) Nakagawa, T.; Kondo, S.; Saeki, S. J. Chem. Phvs. 1982, 76, 3860.

(27) Yarkony, D. R., Schaefer, H. F., III; Rothenberg, S. J. Am. Chem. Soc. 1974, 96, 5974 and references therein. 